\title{
1. Sports economics and the sports industry: perspectives in economic history
}

\section{John K. Wilson}

Sport is a multi-billion dollar industry. Television rights are keenly competed over by rival broadcasters. Textile manufacturers capitalize on the popularity and at times tribal following of sporting teams. Players who were once amateurs often command salaries which dwarf some of those paid to the most highly-paid professionals in the labour market. Governments are heavily involved in the sector - they provide subsidies and allow regulatory exemptions from rules that would be binding for many non-sports sectors. How did this come about?

As the prominence and importance of sport as an industry has risen, so too has public and academic interest. Media and fans pore over statistics and relish the chance to try and predict often unpredictable results. In economics, a significant literature has emerged. Topics range from analysis of major public policy issues such as corruption of governing bodies and subsidies to the sector by governments through to game theoretic predictions over player behaviour. This literature is large and rich with different questions and applications.

This book represents a collection of chapters which examine a variety of sports economics issues through the lens of economic history. It covers a variety of different sports, continents and periods to provide insight into the development and history of sport across the world. The interest generated by sport often leads to record keeping that is not characteristic of other sectors of the economy. The availability of data and records makes sports economics an interesting field to examine a wide range of economic issues: the rewards to athletes and organisers, issues surrounding 
labour markets and labour market restrictions, the running of major events, determinants of crowd attendance, and the institutional arrangements surrounding sport. These issues, it should be noted, are not confined in terms of their interest or importance to sport. Phenomena such as discrimination in labour markets, ideal models of governance, and optimal use of infrastructure have much wider implications in society. The contributors here take a long-run historical view of these issues, something which has been less characteristic of the sports economics literature to date.

\subsection{OVERVIEW OF CHAPTERS}

The late nineteenth and early twentieth centuries saw a degree of transformation in sport. Increasing leisure time and real incomes led to greater participation and a rise in spectator demand. This was nothing short of a revolution in how sport had been played and watched, and how it would be in the future. In Chapter 2, Pomfret outlines these developments, tracing the development of professional team sports from the mid-1850s through to the current day. The chapter raises many issues central to current debates surrounding sport and sports administration: the distribution of rents, models for governance, and issues in public policy.

As sports became more professional, so too did the prospect of players migrating between countries. More recently, players have also begun to show an inclination at times to change codes. Using data from 1958-2004, Kawaura and La Croix (Chapter 3) examine foreign player participation in the Nippon Professional Baseball league (NPB). Their results - which show that foreign players performed relatively well but nonetheless had shorter careers in the NPB than local incumbents - raise questions regarding relative wages and career progression between leagues (in particular between Major League Baseball [MLB] and NPB) and over cultural issues surrounding labour mobility and player satisfaction.

Mega-events are characterized by competition involving a wide array of sports (for example, the Olympics or Commonwealth Games) or knockout competition within a single sport (for example the FIFA and ICC World Cups). Some, however, have reached almost 'mega-event prominence' for a single event within a single sport, such as is the case for the Tour de France. Mignot (Chapter 4) 
chronicles a detailed history of this well-known cycling event. His analysis provides a view on the origins of the race, its financial aspects and the riders and teams, together with institutional factors and challenges for the future.

Sport is characterized by unusual regulations surrounding labour markets. Sport relies on the skill set of players in order to produce entertainment, and a league may try to influence the distribution of talent in order to ensure that outcomes do not become too predictable. For example, in an attempt to maintain competitive balance, many leagues impose allocation systems based on league standings, where lower-placed clubs get earlier excusive picks over playing talent. Salaries for teams or individual players may also be capped below market equilibrium rates to ensure that championships cannot be 'bought'. In the past, more severe restrictions entailed the binding of certain areas to clubs, such that it was difficult for players to move outside their zone. Such practices may reduce intra-league disparity in terms of performance, but they come at a cost. Players have relatively short careers, and restrictions which reduce their earning capacity or mobility surely lower their welfare. In the limit, lower rewards may actually reduce the incentives for entry into sport, or distort choice of sports among athletes with a bias towards less-regulated labour markets.

In Chapter 5, Wilson examines one of the key factors used to support labour market restrictions: the relationship between crowd attendance and closeness of a sporting contest. Using data from the South Australian National Football League (SANFL) from 1920-1983, he shows that, while competitive balance had some role in determining crowds, other factors (for example, traditional or local rivalry) were equally important.

One of the major inputs to the production of professional sports is a stadium. In many countries at various times stadiums have been built, or significantly renovated, mostly at taxpayers' expense. This phenomenon is currently occuring in Australia, where major cities compete in providing better stadiums. Given the fixed-costs nature of investment in a stadium, it would seem optimal not to have long periods where it is idle. The experience of ground sharing varies between countries. In the Australian case, there is a history of ground sharing between Australian Rules football and cricket which has proven relatively popular with governments and spectators, though not always with the codes themselves. In Chapter 6, 
Frost, Lightbody, Halabi, Carter and Borrowman discuss cases from Melbourne, Adelaide and Perth. Their discussion highlights the tensions that exist between codes and the associated issues with ground-sharing arrangements. In particular, they document the conflicts which took place between cricket and football administrators and how in Adelaide a 40-year dispute between the respective governing bodies included the construction of a stadium built solely for football. Resolution to this dispute and a return to ground-sharing arrangements was only concluded courtesy of a publicly funded redevelopment of the Adelaide Oval cricket ground.

An important institutional feature that shaped sport particularly in the twentieth century was the role played by employers in facilitating sport. Vamplew (Chapter 7) provides a long-run account of the role played by employer sports. These played a major role in providing sports facilities and enabling participation in sport, and they have been a somewhat overlooked aspect of the literature to date. Employer groups, particularly in the early part of the twentieth century, were active in promoting sport and were perceptive as to the benefits of such acts that would be provided in terms of worker welfare. Since 1945, workplace provision has declined in importance causing a gap in provision that is only partially met by public spending. Despite common references to the health benefits of sport, government financing of sport is overwhelmingly directed to elite athletes and spectator sports.

Labour market discrimination has been of interest to scholars in a variety of disciplines. Again, in sport, data on performance and individual players' ethnic background provides a rich source to use sporting labour markets to analyze this issue. Cranfield, Inwood and Ross (Chapter 8) explore the issue of discrimination against French-Canadian ice hockey players, where previous literature has suggested long-run discrimination. Using anthropometrics to examine height, weight and BMI among players in the National Hockey league (NHL), Cranfield et al. find that physical differences rather than ethnic discrimination can explain the share of Francophones.

As a whole, the collection sheds light on the evolution of professional and participatory sports across the world. It highlights common features across sports and across countries in response to rising wages and increased leisure time in the late 1800s and the development of radio and television in the 1900s. It also shows how 
the rich treasure trove of sports statistics, often originally collected for obsessive fans, can shed light on economic and social issues such as labour market peculiarities or ethnic discrimination. The contents are, of course, partial and selective, and we hope they stimulate greater interest in and new research on the economic history of sport. 